\title{
Helicobacter pylori-positive inlet patch without concurrent Helicobacter pylori gastritis: case report of a patient with sleeve gastrectomy
}

\section{Thinzar Lin ${ }^{a}$, Sandar Linn ${ }^{b}$, Mel A. Onac, Sushil Duddempudid}

The Brooklyn Hospital Center, Brooklyn, New York, Academic Affiliate of The Icahn School of Medicine at Mount Sinai, Clinical Affiliate of The Mount Sinai Hospital, Brooklyn, New York; Cedars-Sinai Medical Center, Los Angeles, CA, USA

A 54-year-old Hispanic male presented to the clinic with chronic dyspepsia and uncontrolled reflux symptoms not responding to acid-suppression therapy with a proton pump inhibitor (PPI). His past history was remarkable for sleeve gastrectomy one year previously. PPI therapy was stopped two weeks prior to endoscopy to promote the yield of a Helicobacter pylori (H. pylori) test. Esophagogastroduodenoscopy revealed gastric-like mucosa $2 \mathrm{~cm}$ in diameter in the proximal esophagus, suggestive of an inlet patch (Fig. 1). The biopsy of the esophageal lesion confirmed the gastric mucosa, showing mild chronic inflammation and a positive immunohistochemical stain for $\mathrm{H}$. pylori (Fig. 2). Biopsies from the gastric mucosa were only significant for chronic gastritis, with a negative $H$. pylori stain.

Gutierrez et al suggested that $73 \%$ of cases of $H$. pylori gastritis were associated with $H$. pylori infection of an inlet patch and that such an infection is highly related with the density of $H$. pylori colonies in the stomach [1]. To our knowledge and to date, this report is the first case of isolated H. pylori infection in a cervical inlet patch without concurrent H. pylori gastritis $[2,3]$.

The case is also unique because of the prior history of sleeve gastrectomy. The mechanism of isolated H. pylori infection in patients who have undergone sleeve gastrostomy remains unclear; our proposed theory is that the altered stomach anatomy reduces its isolation and promotes $H$. pylori colonization in other parts of the gastrointestinal tract.

\footnotetext{
'Department of Internal Medicine, The Brooklyn Hospital Center, Brooklyn, New York (Thinzar Lin), ${ }^{\mathrm{b}, \mathrm{c}, \mathrm{d}}$ Division of Gastroenterology and Hepatology, Department of Internal Medicine, The Brooklyn Hospital Center, Academic Affiliate of The Icahn School of Medicine at Mount Sinai, Clinical Affiliate of The Mount Sinai Hospital, Brooklyn, New York (Sandar Linn, Mel A. Ona, Sushil Duddempudi); 'Division of Digestive and Liver Diseases, Cedars-Sinai Medical Center, Los Angeles, CA (Mel Ona), USA

Conflict of Interest: None
}

Correspondence to: Sandar Linn, MD 240 Willoughby Street, Apt 18 J, Brooklyn, NY 11201, USA, Tel.: +1 718757 5808, e-mail: slinn@tbh.org

Received 9 October 2016; accepted 21 October 2016; published online 4 November 2016

DOI: https://doi.org/10.20524/aog.2016.0102

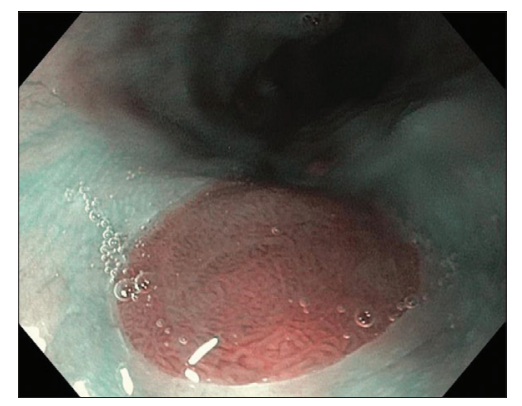

Figure 1 Narrow-band imaging of the gastric-like mucosa in the upper esophagus

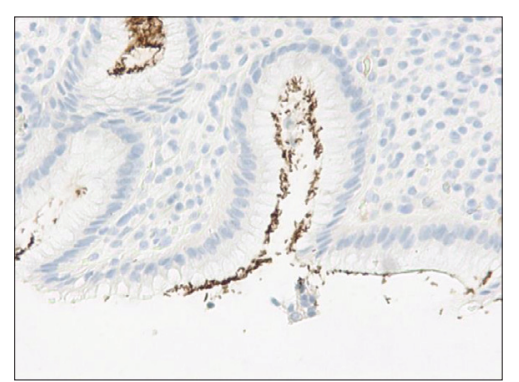

Figure 2 Immunohistochemical stain reveals that the inlet patch gastric mucosa is positive for Helicobacter pylori microorganisms (immunoperoxidase 20x)

Further studies are warranted to confirm the mechanism of isolated $H$. pylori colonization in a cervical inlet patch and its association with sleeve gastrectomy.

\section{References}

1. Gutierrez O, Akamatsu T, Cardona H, Graham DY, El-Zimaity HM. Helicobacter pylori and hetertopic gastric mucosa in the upper esophagus (the inlet patch). Am J Gastroenterol 2003;98:1266-1270.

2. Alagozlu H, Simsek Z, Unal S, Cindoruk M, Dumlu S, Dursun A. Is there an association between Helicobacter pylori in the inlet patch and globus sensation? World J Gastroenterol 2010;16:42-47.

3. Truong LD, Stroehlein JR, McKechnie JC. Gastric heterotopia of the proximal esophagus: a report of four cases detected by endoscopy and review of literature. Am J Gastroenterol 1986;81:1162-1166. 